\title{
Criminalisation of human error in health care: How and why legal accountability can crowd out professional accountability and undermine patient safety
}

\author{
Sigurbjörg Sigurgeirsdóttir, Professor of Public Administration and Gov- \\ ernance, Faculty of Political Science, University of Iceland
}

\begin{abstract}
This research is about accountability in health care. Theoretically it aims to shed light on two types of public accountability, how these types interact and relate to the aim of learning to improve patient safety. The study addresses the theoretical questions how and why legal accountability can crowd out professional accountability. It seeks to answer the empirical question what is the impact of criminal charges against health professionals by presenting two sets of data: First, a case study of an event, first of its kind in Iceland, in which a nurse in an intensive care unit was charged for manslaughter by negligence in May 2014. The court case material is examined and specialised in-depth and semistructured interviews conducted to describe the experience at the level of the individual and to account for organisational responses. Second, explorative focus groups were carried out in preparation of an internet survey conducted among all practising nurses in Iceland measuring the impact of the prosecution. The narrative highlights the complexities and risks of error involved in health care. Survey results show that the prosecution has increased the level of insecurity among nurses and raised awareness of the risk involved to themselves in their job. This court case established a precedent and constitutes a defining moment in the health care system. While accountability mechanisms were in their infancies in the system, health professionals in Iceland lost their immunity
\end{abstract}


with a possible setback for the fostering of effective professional accountability mechanisms and devastating consequences for patient safety.

Keywords: Health care; human error; accountability; trust; organisational learning.

\section{Introduction}

This research is about accountability in health care in circumstances under which unexpected incidents harm or cause death to patients. As a study in public administration the research aims to shed light on the theoretical questions how and why legal accountability can crowd out professional accountability and thereby undermine the purpose of learning from mistakes. With insight from cognitive psychology focusing on the human factor, this paper seeks to bring a better understanding in the context and conditions under which human error in health care occurs, the impact of human error and criminal prosecution on professionals involved and the resulting effects on accountability. For this purpose, the paper firstly gives an account of a particular case in which a health professional was prosecuted for manslaughter by negligence. Secondly it seeks to answer the empirical question asking what is the impact of criminal charges against health professionals by examining results from a survey among practising nurses in Iceland in which the impact of a prosecution against an Icelandic nurse in May 2014 is measured.

The paper is structured as follows: the research material and methods are described followed by a section on the theoretical perspective in which public accountability is defined as a mechanism of social relations and how the human factor perspective affects its operation. The following two sections provide the data. The former, narrates a case history, in which an incident at the National University Hospital in Iceland and its aftermath is described, while the latter presents the results and analysis of a survey conducted in order to measure the impact of the criminal prosecution among Icelandic nurses. The presentation of the data and the analysis is followed by a discussion in which the theoretical questions are addressed. A concluding section summarises the arguments.

\section{Research material and methods}

The research is based on two different research strategies, a case study and a survey. A case history draws predominantly on the court material consisting of a reprint of Judgement from the District Court of Reykjavik (2015), files and documents from an attorney defending the nurse including a complete collection of media coverage. The story and its context was completed and verified with further information from police reports, a forensic autopsy report, six in-depth and semi-structured interviews with a purposive sample of individuals (Robson 1993, 141-142), including the nurse herself. Clarifying and validating the interview data were undertaken with a further eight individuals, with some being interviewed more than once. Interviews took place from November 2018 to July 2019. The case history is presented as a narrative, accounting for an unexpected incident in health care by narrating the course of events in a chronological order from the perspective of professionals involved. In-depth and semi-structured interviews were 
transcribed verbatim. Interviewees were promised confidentiality and that information gathered from the interviews will not be traceable to a particular interviewee.

The internet survey is based on a unique set of data as it includes the whole population of practicing nurse in Iceland, not just a sample. Three explorative focus group interviews (Krueger 1994) were run in preparation for the survey. Two focus groups with nurses including six and seven participants, and one with assistant nurses including six participants. The survey, conducted by a research company í Reykjavík, took place from February $26^{\text {th }}$ to April $3^{\text {rd }}$ 2019. A questionnaire with three questions was used to measure the impact of the prosecution among nurses. It was sent by emails to 2,882 practicing nurses, members of the Icelandic Nurses' Association and followed up by four reminders, two text messages and some telephone calls. In total 1,958 nurses responded to the questions: a response rate of $68 \%$. The survey data were processed by the company.

The first question in the questionnaire asked the nurses directly about the size of the impact that they feel the prosecution had had on themselves. The second question asked the nurses about the size of the impact that they believed the prosecution had had on nurses in general. The nurses could respond to these questions on a five point Likert Scale anchored by very much impact and no impact at all. The third question in the questionnaire asked: if any impact, then what kind of impact in your opinion? This question provided six options; five statements and one open text option. There were more responses than respondents because nurses could tick all the options and write their own text in the sixth option. Valid responses were 3.586, but the number of respondents was 1.711 .

More than $16 \%$ of the nurses addressed further issues in relation to the impact of the prosecution with 272 written responses in the open text option. The open text responses were examined and coded by the author and a research assistant separately in order to extract the most dominant themes in the text. Primary (main) codes were identified and counted. Based on five primary codes obtained from the analysis of the text two main themes emerged (See Table I). Secondary codes in the Table include direct quotations from the open text responses.

\section{A theoretical perspective: Public accountability and the human factor}

Drawing on cognitive psychology, Dekker (2012) is concerned with the human factor and accountability requirements in circumstances where two different objectives are in conflict. Examining the challenge involved in achieving organisational learning in safetycritical systems Dekker illustrates with evidence from aviation, health and child care the competing nature of the two different objectives of justice and safety and its consequences for safety. He argues that "Only responding to calls for accountability is not likely to lead us to justice or improved safety. People will feel unfairly singled out, and disclosure of safety problems will suffer" (Dekker 2012, 9). Here the quest for accountability takes only one meaning which is to pin down who is to blame. Concerned with 


\section{STJÓRNSÝSLA}

the clash between objectives and the effect of pursuing both objectives at the same time, Dekker however believes that calls for accountability and responding to them is important. But taking into account the human factor, he argues that "calls for accountability themselves are, in essence, about trust" and makes the case that this trust is in jeopardy when pursuing the two objectives of justice and safety at the same time. (Dekker 2012, 8).

Dekker pays a particular attention to the "second victim" and points out that "When a professional mistake is put on trial, safety almost always suffers. Rather than investing in safety improvements, people in the organization or profession invest in defensive posturing, so they themselves are better protected against prosecutorial attention" (Dekker 2012, 11) ${ }^{1}$. Dekker goes on to say that the more cases are taken to trial, the "more we could be creating a climate in which freely telling each other accounts is becoming more and more difficult" (Dekker 2012, 33). His line of reasoning is that learning from mistakes and improving safety require a system in which accountability is about trust.

Dekker maintains that for most professionals "an error that leads to an incident or death is antithetical to their identities". They may see it as devastating failure and the "memory of error stays with professionals for many years" (Dekker 2012, 76) ${ }^{2}$. His argument is not about professionals being accountability-free, rather it is about securing a blame-free culture (Dekker 2012, 83), so as to enhance organisational learning. As reasonable as that may sound, achieving what Dekker calls "Just culture" is however according to him far from being straightforward. His concern is how an act is turned into an error and an error into a crime and who draws the line between an act and a crime. He points out that the view exists in the legal community that criminalisation of error is "a long-overdue colonisation of rogue areas of professional practice" (Dekker 2012, 107). According to this view the law is "authoritative, neutral and fair and should reign everywhere with no exception or discrimination either way". In other words, criminalisation of error does not take place in a vacuum. Which type of accountability applies, professional or legal accountability depends on who tells the story and in which terms.

These questions bring up the theoretical perspective taken in this research, i.e. the public accountability perspective. In this perspective the term "accountability" is considered and understood as a general term for any mechanism that makes powerful institutions responsive to their particular public (Bovens 2007). More specifically, we consider accountability as "a relationship between an actor and a forum, in which the actor has an obligation to explain and justify his or her conduct, the forum can pose questions and pass judgement, and the actor may face consequences." (Bovens 2007, 450). Furthermore, we are concerned with different types of accountability mechanisms and how they interact. Each mechanism uses a standard set of questions which calls for specific answers, depending on the objectives of the respective accountability mechanism. In the circumstances in which different objectives are being pursued applying two different accountability mechanisms simultaneously, the question arises whether and how the competing objectives of the two may affect the outcomes. Can two different objectives pursued by two different accountability mechanisms be achieved at the same time? Here it is helpful to specify the different types of accountability and how they operate. 
Bovens (2007) describes at least five different types of accountability of which two are relevant for this research. Bovens argues that the type of accountability mechanism is generally defined by the types of accountability forums, i.e. the forums calling an actor to account. He identifies professional accountability with professional bodies as accountability forums and legal accountability where the courts are the accountability forums. These two types of accountability guide the analysis in this research.

Concerning the interaction between legal and professional accountability more specifically, Hood (2014) has identified this interaction by specifying the mechanisms by which these two types of accountability operate. By considering accountability and blame-avoidance in a polar opposition, Hood discerns the dynamics between blameavoiders and accountability-seekers as some sort of a zero-sum game between the two. In this view accountability takes only one meaning and that of an attempt to pin down blame (Hood 2014, 608). Moving beyond this polar opposition, Hood distinguishes between two dimensions of accountability, the answerability dimension concerned with explanation and diagnosis and the dimension concerned with establishing culpability. He points out that answerability figures in a well-known practical application of "no-fault models" of reporting, and materialises in various forms of voluntary and anonymous reporting systems for safety-critical mishaps such as medical error and aviation near-misses. Hood's conception of these two dimensions of accountability relates to Boven's types of professional and legal accountability. More specifically, in Hood's conceptualisation, answerability is a specification of the mechanism by which account is rendered by the former and culpability by the latter.

Hood draws on Sagan's argument (1993) behind safety culture and high-reliability organisations in organisational theory in which promises of immunity from prosecution are essential in order to secure quality information about past errors or malfunctions to enable organisational learning. Hence this is why no-fault reporting is so commonly identified as a key feature in safety-culture. Hood goes on and makes the argument that "accountability systems designed to promote learning and adaptation on the basis of rich information flow may have to stress the answerability dimension of accountability at the cost of the culpability dimension". To the extent this is achieved, Hood argues that blame-avoidance and accountability will not be polar opposites (Hood 2014, 610). Hood is ringing Dekker's bell about the importance of securing a blame-free culture and that learning from mistakes and improving safety require a system in which accountability is about trust.

The relationship between trust and accountability is however far from being straightforward as Greiling (2014) points out. In her view trust is essential when the objective is organisational learning and that it "can only happen where public accountability goes beyond pointing an accusatory finger. A learning culture in the public sector requires a general readiness to encourage questioning and constructive criticism". All stages of account-giving are affected, and she goes on to say that "the information input of the account-giver needs to be based on honest, unbiased provision of all the relevant facts including the admission of error" (Greiling 2014, 627). In short, for accountability as a 
mechanism of social relations to work effectively in a process of organisational learning there has to be a climate of trust.

How different accountability mechanisms operate provides a deeper theoretical understanding about how and why these mechanisms affect policy outcomes. But, appreciating different types of accountability is not enough. Before narrating an unexpected incident in health care, a social science research needs a differentiated conception of human error as a concept in health care. That said, it has to be acknowledged that bad motives exist as notorious cases of serial killers in health care have shown. However, compared to unexpected serious incidents in health care those are rare.

Conceptualising human error in health care, this research draws on work in safety management that has created a sophisticated definition of human error in this field. In health sciences differentiating between slips or lapses, mistakes and accidents has been well established (Institute of Medicine 2000, 54). A slip or lapse occurs when the action conducted is not what was intended. It is an error of execution. But there is a difference between a slip and a lapse in that a slip is observable and a lapse is not. For example, turning the wrong knob on a piece of equipment would be a slip; not being able to recall something from memory is a lapse. In a mistake, the action proceeds as planned but fails to achieve its intended outcome because the planned action was wrong.

A further differentiation of how humans contribute to error distinguishes between active and latent errors. "Active errors occur at the level of the frontline operator, and their effects are felt almost immediately. This is sometimes called the sharp end. Latent errors tend to be removed from the direct control of the operator and include things such as poor design, incorrect installation, faulty maintenance, bad management decisions, and poorly structured organizations. These are called the blunt end." (Reason 1990 in Institute of Medicine 2000, 54-55, emphasis in original).

When considering a role of systems and the human contribution to accidents, a system is seen as " a set of interdependent elements interacting to achieve a common aim. The elements may be both human and non-human (equipment, technologies, etc.)." (Reason 1990 in Institute of Medicine 2000, 52, emphasis in the original). An accident is: "an event that involves damage to a defined system that disrupts the ongoing or future output of that system." (Perrow 1984 in Institute of Medicine 2000, 52, emphasis in original). Accident investigations now look for the latent errors in organisational systems because changing these will reduce the likelihood of further errors.

We now turn to the empirical part of the research and describe the two sets of data assembled: a narrative account of an unexpected incident at the National University Hospital in Iceland and its aftermath and the survey results measuring the impact of the prosecution accounted for in the narrative on nurses in Iceland.

\section{A Case History: How things can go wrong when a patient dies}

We call her Anna. It is 2012 and Anna is 35 years old, married and a happy mother of two young children. She had followed her childhood dreams to become a nurse, had her training in Denmark and later specialised in anaesthetic nursing at the University Hospital in Iceland. As described by her colleagues Anna is cheerful, competent, com- 
passionate and always ready to step in and help. As a nurse at the University Hospital, Anna is in her elements.

On October $3^{\text {rd }}$ 2012, after completing a tough eight hour-shift in Anaesthesia, Anna was asked to take an extra shift at the Intensive Care Unit (ICU). Anna agreed and took over the care of Patient X from Kristin, a nurse finishing her day shift. The handover Anna got from Kristin was short, so having no prior knowledge about Patient X Anna had to do her own review.

Patient X was a 74 years old male with multiple diseases. He had undergone an open heart surgery with complications and was being weaned from the respirator. A PassyMuir speaking valve had been attached to his tracheostomy tube to enable speaking. When Anna arrived the patient's wife was visiting. Anna did all the routine security checks, except checking the alarm settings on the monitor. The monitor was on the other side behind the patient's wife and since they were talking, Anna decided not to interrupt but to come back later for a full security check on the monitor. In Anaesthesia it is a standard operating rule to never turn a security alarm off and Kristin had not mentioned anything unusual about the alarm.

As Anna left the room, she was asked by her manager to help out monitoring post operation in Recovery. Anna left her colleague, Maria, who was caring for Patient Y in the same room, in charge of her Patient X. On Anna's arrival at Recovery, problems had been sorted, so Anna returned to ICU. When back she was asked to assist a colleague to bring Patient Z, who was on a respirator, for a CT scan in Radiology in the basement of the hospital building. On her return to ICU this time she had to help another colleague with a broken dialysis machine. Having done that Anna was asked to transfer a patient to Recovery. On her arrival with the patient on a trolley to the Recovery all beds were full, so she was asked to take the patient over to Recovery at the Women's Hospital (WH) in another building. She pushed the trolley through an underpass to WH. When Anna arrived at WH, she was asked to attend to another patient in the WH's Recovery before leaving back to ICU. While there, Maria called her from ICU asking whether she could give Patient X painkillers and whether she was allowed to connect him to a respirator as he still had the speaking valve. Anna told her to make her own judgement about this and that she would agree to her conclusion.

At 6:30 pm, Anna was back at ICU and finally now able to attend to her patient properly. At this point, Patient X had been on the respirator for two hours. While helping Patient $\mathrm{X}$ she disconnected the respirator and plugged in the speaking valve at $8 \mathrm{pm}$. Anna had performed this procedure so many times before and thus went through the routines almost automatically. The checklist for the procedure was in a folder in a closed drawer by the bedside. She had not got the time to run through it carefully due to the hectic conditions constantly interrupting her while attending Patient X. She was about to remove the speaking valve and reconnect her patient to the respirator when she was yet again interrupted. There were no signs that Patient $\mathrm{X}$ had breathing difficulties while she, Maria and a third nurse Helen, were standing there by his bedside. Helen, a nurse in charge of Patient $Z$ next door, had entered the room asking for someone to come over 


\section{STJÓRNSÝSLA}

and assist her with Patient Z. Anna volunteered and Maria again took over the care of Patient X.

Shortly after, Maria called out asking if there was something wrong with the arterial line measuring the blood pressure. Few minutes later Maria called out again, "Come over, please, it is acute!". They rushed over and Anna noticed that Patient X was cyanotic, - an emergency code was called. In a matter of a few seconds the room was crowded with emergency staff and resuscitation was performed, but with no success. Her patient died.

Next morning, Ragnar, an anaesthetist who was on call and in charge of the resuscitation of Patient X, told the ICU Medical Chief that an incident had occurred the night before that might need further examination. The ICU Medical Chief and the Nursing Manager decided to call in both Maria and Anna to discuss the incident. Maria came in first, described the incident and drew their attention to the cuff on the speaking valve which she thought had not been emptied when put on Patient X earlier in the evening. The cuff is a tiny balloon on that part of the valve that is placed inside the patient's trachea. It is filled with air when the respirator is on, but emptied when the speaking valve is on. If not emptied, the patient can only inhale not exhale.

This same morning at about 9:30 Anna had been asked to meet up for a debriefing on the incident the night before. On arrival to ICU she felt the atmosphere was somewhat bizarre. Later she learned that police detectives had been there earlier in the morning. Anna met with the Manager and the ICU Medical Chief. They asked Anna for a detailed account of all actions she performed the night before. When the conversation came to focus on her care for Patient X, Anna was asked whether she had emptied the cuff when she put the speaking valve on at $8 \mathrm{pm}$. Anna understood the question as an established fact being reported to her based on an already performed examination, so she lost her breath and replied in shock "Oh my God, did I forget to empty the cuff!". Suddenly she could not remember whether she did empty the cuff or not. In a state of panic, Anna blamed herself, assuming that what they told her was really the way it happened. She was guided out through "a back door" and referred to a counsellor. On her way out Anna was told that the incident would be reported to the police.

The case was documented in a police report October $4^{\text {th }}$ at 12:32. The ICU Medical Chief, as supposed to by law, had reported the incident to the Chief Medical Officer earlier that morning, who then reported the incident to the Directorate of Health and to the police. The police report included Anna's full name and information describing in details that a patient had died because of a professional mistake by a nurse on duty who had not followed the exact technological procedures necessary to keep the patient stable and alive. Later this afternoon Anna, was called by a police detective summoning her to the police station. Being informed that since she was now a criminal suspect the police had assigned her a lawyer. The following morning (October $5^{\text {th }}$ ), Anna went to the police station to give evidence. She was alone, without professional support and still believing that she had forgotten to empty the cuff and thus the one responsible for the death of Patient X.

Few days later, Anna was encouraged by her ICU nursing manager to start writ- 
ng everything down immediately, recalling all the bits and pieces from what she did while taking care of Patient X. Anna started the writing and went through the course of actions over and over again. The more Anna wrote down the more puzzled she became: there was something in this story that did not add up. As the weeks passed she decided to withdraw her earlier statement in which she had admitted that she must have forgotten to empty the cuff. But her lawyer strongly advised her not to withdraw her statement. Although few actually believed Anna would be prosecuted, some colleagues however advised her to find another lawyer, which she did.

On May $20^{\text {th }} 2014$, the State Prosecutor launched criminal prosecutions against Anna and the University Hospital as well (CPP 2014). Anna was charged for manslaughter by negligence according to the Penal Code and the Law of Nursing. The criminal charges against Anna became a media frenzy and her name became public. Months passed with growing agony among the staff and devastating anguish for Anna. On Wednesday morning, December $9^{\text {th }} 2015$, came the verdict. Anna was acquitted.

Anna had had reasons to be puzzled about what had really happened that night in October 2012. The verdict describes how reactions of those in charge at the hospital had been hasty and how the attention had become fixed on one possible explanation only. No consideration had been given to other possible causes of death of Patient X. On the contrary, the police detectives who had been at the hospital in the early hours of October $4^{\text {th }} 2012$ before Anna's debriefing with the Manager and the ICU Medical Chief had been told that a mistake had been made (CPCR 2012a). A nurse had forgotten to empty a balloon on a speaking valve. In court a police detective referred to the report in which Anna had admitted this in evidence she had given the police the morning after. So she had been the only suspect under investigation. Moreover, when asked by the judges whether anyone else had been interrogated, the police detective responded that the case was fairly "clear-cut", about who was responsible, so no one else was believed to be a suspect.

The police had requested a forensic autopsy on Patient X's body. This formal request included the same details described in the police report explaining how and why the patient died. Post mortem examinations reported an abnormal death (Research Institute of Pathology 2012). When asked in the court about the causes of trapped air in Patient $\mathrm{X}$ 's lungs, a forensic medical examiner explained that it could been caused by what was described in the formal request from the police, i.e. the mismanagement of the respiratory equipment so that the patient could only inhale not exhale. But, as it happened, there was no physical evidence in support of the cause of death Anna was charged for since the speaking valve and other medical devices had been removed and disposed of. After all, nobody at that moment had suspected the death of Patient X was abnormal.

An internal root cause analysis of the incident, the first one of its kind in Iceland, which had been completed long before the criminal charges against Anna were launched in May 2014, had come to different conclusions. The timing of Patients X's cardiac arrest occurred about 30 minutes after Anna had put on the speaking valve, the moment she is supposed to have forgotten to empty the cuff. If the cuff hypothesis were right 


\section{STJÓRNSÝSLA}

the patient would be dead within 15 minutes. A plausible explanation could be that a plug of mucous might have moved up from the patient's airways and obstructed the tracheotomy tube above the speaking valve. But this was impossible to prove since all the devices had been disposed of.

However, the alarm on the monitor signalling low oxygen saturation levels should have alerted the staff in time. Anna had never got the chance to complete the security check of the monitor at the beginning of her shift and it turned out that the alarm was turned off, something that is never done in Anna's own unit, Anaesthesia. Nobody told her that the alarm was turned off. In the evidence to the police, Kristin, the nurse who had given handover to Anna at the end of her day shift on October $3^{\text {rd }} 2012$, told the police she (i.e. Kristin) knew that the alarm was not on and that she hadn't been worried about that (CPCR 2012b). In the court, Kristin maintained her evidence in the police report and confirmed that this alarm had not been mentioned in her handover to Anna. She, Kristin, had no idea who might have turned it off. It can only be turned off intentionally and nobody knows who turned it off. The monitor had been sent to the manufacturer for an investigation but no failure had been reported.

In the early morning of December $9^{\text {th }} 2015$, before the verdict came out, Anna's colleague, Ragnar, the anaesthetist who informed about the case in the first place, had been found dead. Now five years later Anna has changed. The job of her childhood dreams had ruined her personal life. Her marriage broke down and the relationship with the children was disrupted. Throughout the court case, her colleagues at the Anaesthesia and ICU had taken her into "intensive care" encouraging her to come back to work. But Anna was broken, personally and professionally, and is not practising as a nurse anymore.

\section{Survey results: the impact of prosecution}

As we have seen, although acquitted from criminal charges by a verdict, the prosecution itself had enormous consequences for Anna. The purpose of this research was to examine the impact of this prosecution on the profession as a whole. A survey was undertaken in early 2019 in which a questionnaire with three questions was used to measure the impact of the prosecution among nurses in Iceland.

The first question concerned the size of impact of the prosecution on the nurse her or himself. The results from the first question show that over $88 \%$ of respondents say that the prosecution had a very big or a rather big impact on them (Figure 1). 


\section{STJÓRNSÝSLA}

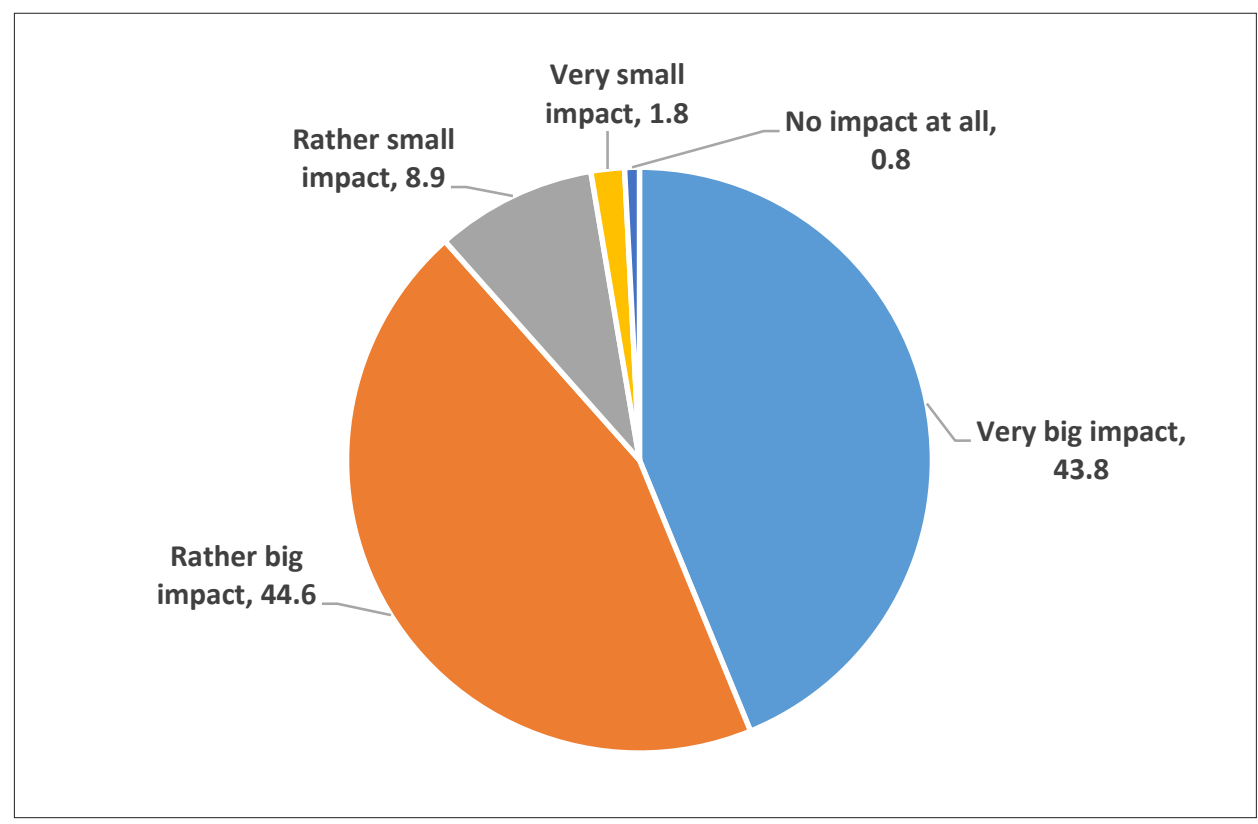

Figure 1. How big or small impact did the prosecution have on you in your job as a nurse?

Nearly $44 \%$ say the prosecution had a very big impact and $45 \%$ a rather big impact. Figure 1 also shows that less than $1 \%$ say it had no impact at all.

Examination of the background data shows that the oldest and the youngest age categories, those over 60 and those under 30, report proportionally slightly more often that the prosecution had a very big or rather big impact, 90.5 and $89.7 \%$ respectively, with the other age categories slightly lower. However, the youngest age category is the smallest group of total respondents to this question only comprising $4.7 \%$. Three age groups are equally big, or nearly $25 \%$ each $(40-49=24.9 \%, 50-59=24.7 \%,>60=24.1)$, constituting almost $75 \%$ of total respondents to this question.

Differences in attitude can be observed as to where nurses work, whether in a hospital, a nursing home or a primary care centre, and whether located in the capital region or in rural areas. The majority of the nurses who feel the prosecution had a very big or rather big impact on them work in hospitals and in the Capital Region.

Respondents were also asked for their view on the size of the impact on nurses in general. More than $93 \%$ of the nurses believe that the prosecution has had a very big or rather big impact on nurses in general (Figure 2). 


\section{STJÓRNSÝSLA}

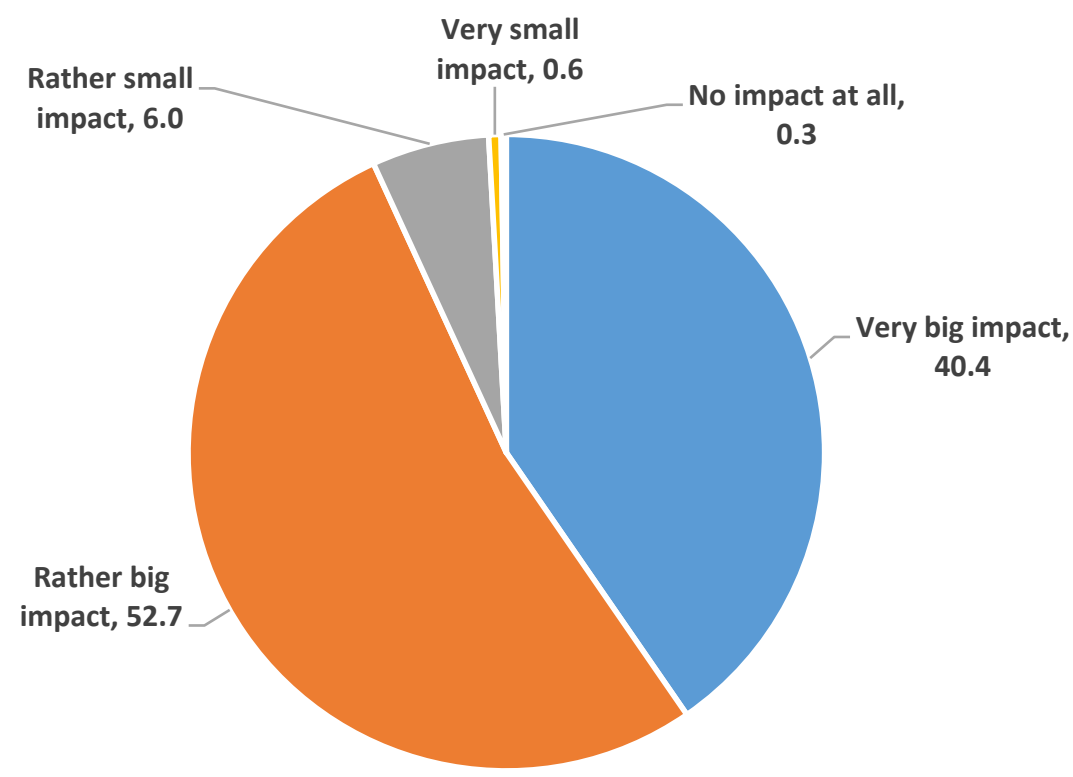

Figure 2. In your opinion, how big or small impact has the prosecution had in general on nurses in their job?

A higher proportion of nurses believe that the prosecution has had a rather big impact $(53 \%)$ than a very big impact $(40 \%)$ on nurses in general.

Analysis of background data shows that over $90 \%$ of all age categories believe that the prosecution had a very big or rather big impact on nurses in general in their job, ranging from $90.7 \%$ of the $40-49$ age category to 95.5 of those over 60 . Although quite similar, it seems that nurses over 60 , more than other age groups believe that the prosecution has had a very big or rather big impact in general on nurses in their job. Similar to the previous question, nurses who feel the prosecution had a very big or rather big impact on them also seem to have in common that the majority of them work in hospitals and in the Capital Region.

The third question in the survey explored the kind of impact nurses believe that the prosecution has had on nurses in general in their job (Figure 3). Only the nurses who in question 2 responded they thought the prosecution had had an impact on nurses in general could respond to this question. 


\section{STJÓRNSÝSLA}

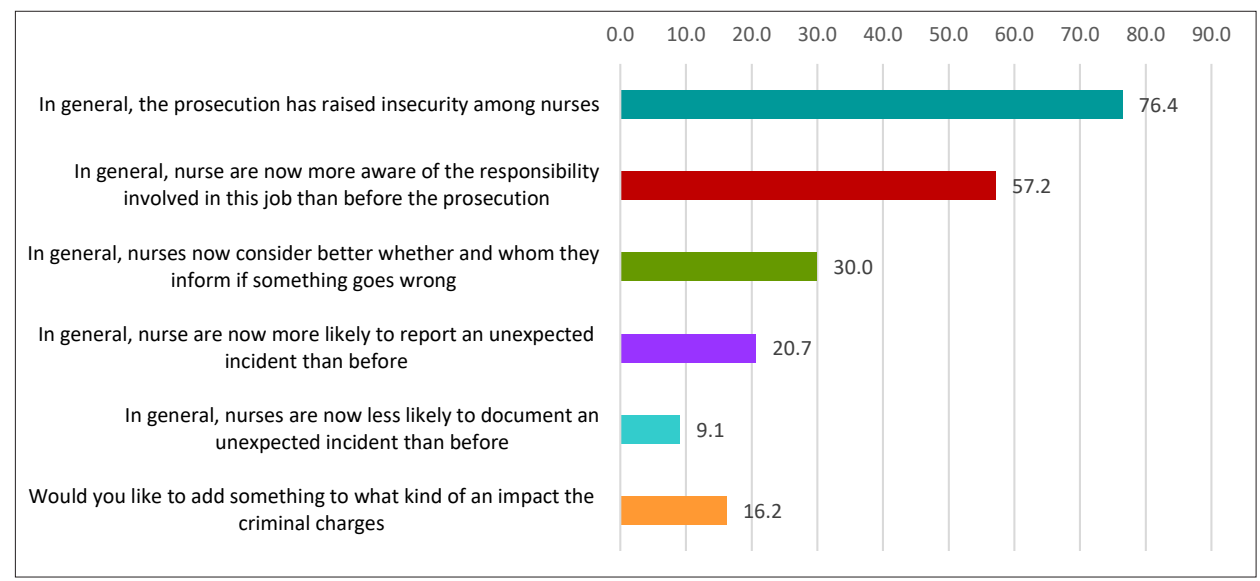

Figure 3. If any kind of impact, then what kind in your opinion?

Of the responses $76 \%$ think that the prosecution has in general triggered insecurity among nurses. Figure 3 also shows that a considerable proportion of nurses $(57 \%)$ believe that the prosecution has raised awareness about the responsibility involved in their job. Furthermore, nurses seem to be more cautious in their job after the prosecution, since $30 \%$ of them believe that nurses now consider more carefully whether and whom they inform if something goes wrong. Some $20 \%$ think nurses are more likely than before to report about an unexpected serious incident while only $9 \%$ think they are now less likely to document an incident. More than 16\% addressed further issue in an open text option.

Based on five primary codes obtained from the analysis of the open text option, two main themes emerged (Table I). First, the increased awareness of risk was found in 164 of the 272 responses (60\%), and second, increased insecurity in the job was found in $106(39 \%)$. However, these themes are closely interconnected in the text.

The former primary theme, the increased awareness of risk, seems to be associated with demanding working conditions of nurses $(70 \%)$ and then to their awareness of professional responsibility $(30 \%)$. 
Table 1. Primary themes and codes

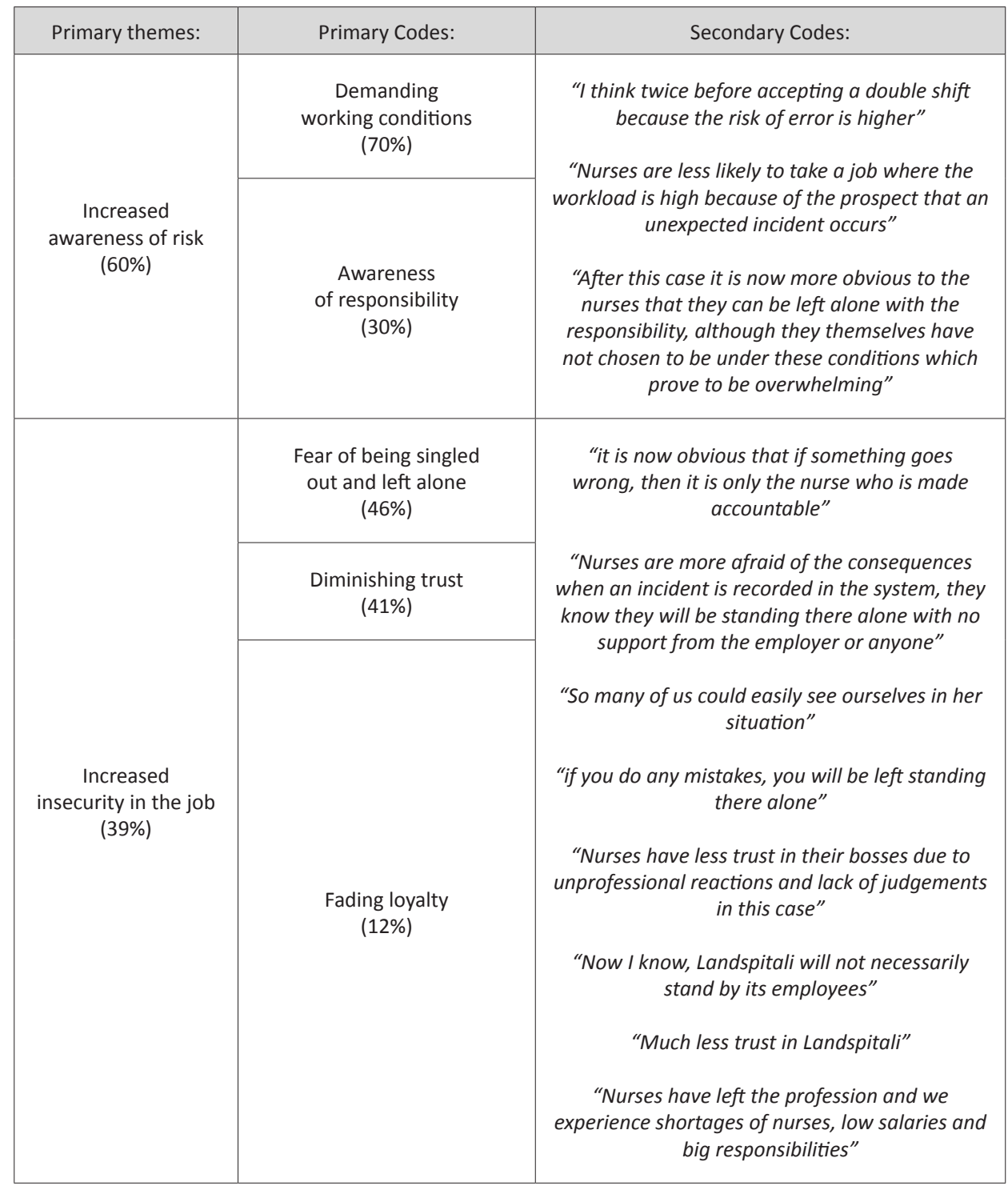

However, like the themes the primary codes are also closely interrelated. The most frequently mentioned issues regarding demanding working conditions were heavy workload i.e. working many extra hours or double shifts and nurses being responsible for too many patients, increased burden due to staff shortages, nurses are performing their work at high speed and having to rush in haste between patients. Also mentioned are frequent interruptions while performing tasks which require careful attention like preparing medicines. Finally, communication challenges are mentioned in relation to transfer- 
from managers and medical doctors.

Signs of a vicious circle can be observed with an escalating risk of error as mentioned a number of times in the text. The pressure on nurses from managers to work extra hours, even double shifts, seems to be very high. Nurses on the other hand seem to be more critical now as to how much tasks to take on and are more cautious when asked to take extra shifts. Demanding working conditions do not seem to be new to the nurses; rather nurses seem to be more aware of the risk of error under these conditions now than before the prosecution. Therefore, nurses are becoming increasingly more reluctant to take on extra hours now than before the prosecution; hence more problems with staffing a shift resulting in an increased risk of error. (Table 1, Secondary codes).

A strong sense of professional responsibility raises the awareness of risk. As mentioned above, concerns about demanding working conditions seem to be closely linked to the other primary code identified in the text and that is a strong sense of professional duties and responsibilities. However, this strong sense of professional duties and responsibilities identified in the text is not accompanied by a sense of professional ambitions and commitments, rather with a sense of resentments which in the material evidently turned into a growing awareness of risk involved in their job. Moreover, like demanding working conditions, awareness of risk for patients involved in nursing was not new to the nurses. The breaking news here is the growing awareness of risk to themselves, professionally and personally, in case something goes wrong. This growing awareness of risk to themselves when working under conditions which are not within their control stands out as an alarming discovery in this text as directly expressed in a secondary code in Table 1.

The latter primary theme, the increased insecurity in the job, emerged from three primary codes in the text $(39 \%)$. First, after the prosecution nurses seem to fear that if something goes wrong on their watch they will be singled out and left alone accountable for what happened (46\%). Several times this fear is expressed unambiguously in the text. (Table 1, secondary codes). Second, this fear seems to be coupled with resentment and disappointment with the employer (most often explicitly mentioned Landspitali University Hospital) and translate directly into distrust as expressed in the quotes. And finally, over again a sense of disappointment, the feeling of having been let down by the employer was expressed and thus not being able to trust their managers or the organisation. These feelings as expressed in the text seem to feed into fading loyalty among the nurses both towards their own profession, the employer and health care in general.

Given the strong sentiments in the text expressing the sense of resentments, anxiety and frustrations, the fact that $20 \%$ still think nurses will be more likely to report an unexpected incident than before appears somewhat incoherent. This incoherence might be explained by the time passed since the prosecution, or it could be an effect of the different terms being used in the statements. Interestingly, 30\% believe that in general nurses now consider better whether and whom they inform if something goes wrong, while some $20 \%$ believe nurses are now more likely to report than before and some $9 \%$ 
believe nurses are less likely to document than before. Technically these terms involve different steps in the process of accounting for an unexpected incident, in which the step to inform comes before the more formal act of documenting and then finally reporting an incident. The possible impact of this differentiation and a close examination of the accounting process was not explored in this research and therefore the research material does not allow for a meaningful interpretation including analysis of background data.

Meanwhile, administrative documentation of unexpected incidents at the two intensive care units operating at Landspitali Hospital shows a significant drop in documentation. First, at the intensive care unit where the incident occurred, documentation dropped almost immediately after the incident in October 2012. Second, documentation dropped again after the prosecution in May 2014, and this time even more significantly at the other intensive care unit of the hospital operating just a few kilometres way. This drop in documentation immediately after the incident and the prosecution was further confirmed in the interviews conducted in this research.

\section{Summary of survey results}

The great majority of the nurses responding to this survey reported that the prosecution had a very big or rather big impact on them in their job as a nurse. The same applied when asked about their opinion whether the prosecution had had an impact more generally on nurses in their jobs.

The prosecution seems to have increased insecurity among nurses in their jobs and made them become more aware now than before about how demanding working conditions increase the risk of error and impose a greater risk, not just on patients, but on themselves, professionally and personally. Moreover, one of the major sources of increased insecurity seems to arise from a fear of being singled out and left alone accountable if something goes wrong. This fear seems to be associated with diminishing trust towards their managers and the organisation as a whole.

\section{Accountability in health care: When the Legal meets the Pro- fessional}

The narrative above tells a story of a serious incident in health care from the perspective of professionals involved. The survey results in the previous section show the consequences of criminal prosecution. The nurse in the story was alone made accountable for what happened, prosecuted and charged for manslaughter by negligence. For the matter of space, priority is given to the core purpose of the theoretical questions this research seeks to illuminate. Therefore, we focus on issues relevant for the how and why one accountability mechanism can crowd out another and thus undermine the purpose of the latter. For the purpose of our analysis we address the how and why question separately while considering the data and the theoretical perspective.

To recap, public accountability is understood as a mechanism of social relations. Different types of accountability (Bovens 2007) operate different mechanisms in order to achieve different objectives (Hood 2014). A human factor approach in cognitive psy- 
chology (Dekker 2012) brings insight into how accountability requirements pursued in order to secure quality information can generate dynamics which upset the effectiveness of accountability. More specifically, when the objective is organisational learning and thereby learning from mistakes and improving safety there has to be a climate of trust for an accountability mechanism to be effective (Greiling 2014).

When the objectives are learning from mistakes and improving safety, professional accountability is appropriate in which the answerability mechanism is operated. When the objectives are deterrence, justice achieved by punishment, then legal accountability in which the mechanism of culpability applies. Deterrence in the context of organisations providing professional care for people is more likely to have the effect of deterring professionals from seeking a job in high risk units within those organisations, as Dekker (2012) has shown in the context of child care services. This might increase the risk of error due to shortages of adequately skilled staff. Furthermore, in circumstances in which quality information is critical for improving safety and learning from mistakes, professionals are less likely to provide that information if information provided will be used against them in legal action. On the other hand, when a sense of safety from prosecution exists, defensive routines among the professionals are less likely to take over and a climate of trust is more likely to be achieved enabling organisational learning (Dekker 2012; Greiling 2014; Ozeke et al. 2019). That said, one must wonder how and why can legal accountability crowd out professional accountability?

First, how can legal accountability crowd out professional accountability? How did legal accountability in our narrative take over at the cost of professional accountability? Like most behavioural scientists, Dekker $(2012,149)$ is sceptical of rational-choice assumptions when dealing with human behaviour. When making decisions people are not meticulously calculating their preferences and priorities. Rather, they move forward tentatively with incomplete assessment of situations, testing what works and take it from there. So, in our narrative we are not witnessing bad people deliberately exercising their power, rather humans characterised by bounded rationality, limited in their capacity to process information, affected by their own sentiments or imperfect memory (Kahneman \& Tversky 1974; Simon 1976; March 1994). To single out and select a scapegoat for an incident is a process which, in the short run, may serve the organisation or the system. The "bad apple" has been removed, so things are under control, the organisation can be trusted. It may also serve colleagues in "thank God it wasn't me!". But more importantly, it serves the rationale for police investigations and legal action, in which the concepts of manslaughter by neglect and intention dominate while human error, mistakes, slips, lapses or accidents as concepts have a more ambiguous standing.

In our narrative we can trace the process by which one individual is singled out from the moment the first account was given by colleagues the morning after the incident. An incident is framed as a mistake, described as neglect and assigned to one particular nurse by name, reported by the name to the police almost simultaneously, documented in the police report in which the nurse had become the only criminal suspect and the details repeated by words in the police's request for forensic autopsy. In this process, 


\section{STJÓRNSÝSLA}

an account of an unexpected incident moved from one public system to another, from the health care system to the criminal justice system. These two systems apply different accountability mechanisms in order to achieve two different objectives as pointed out above. When the issue had crossed the boundaries of these two systems it was out of the control of those who started the process in the first place, albeit with different objectives, inside the health care system. This is what concerns Dekker $(2012,107)$, i.e. how an act is turned into an error and an error into a crime.

Why did this happen? We consider six reasons for why this happened in our story. First, it is stipulated in law since 2007 (Act No. 41/2007) that serious incidents in health care should be reported to the Directorate of Health and also to the police. However, a more sophisticated rules and procedures the reporting to the police should follow in order to safeguard the different objectives of the two systems involved don't exist.

Second, professional procedures to examine serious incidents had not been established inside the hospital. Conceptualisation of human error and professional deliberations about patient safety and safety-culture were in their infancies, confined to a narrow circle of professionals. New generation of professional directors at higher levels in the organisation, advocates and entrepreneurs, were promoting a new approach to patient safety, creating organisational trust by advocating openness and the importance of sharing information about incidents.

Third, compared to poorly developed professional accountability mechanisms inside the hospital, police investigations and legal proceedings have been stipulated and reviewed in laws for decades and thus firmly institutionalised (Act No. 88/2008). While professionals inside the hospital were "in their bubble" still conceptualising the new approach to patient safety, promoting honesty and open culture, the criminal justice system outside the window had its institutions, resources and practices in place, ready to go. The moment it got the incident reported from the hospital the train of legal action set off and moved at its own pace towards its own destination of justice. For the professionals at the hospital is was like "getting run over by a truck coming in from the side and we were in a ditch" as phrased by a senior director.

Fourth, the swift actions taken by the police in this case is said to have had a particular reason as explained in three of the interviews. Prior to the incident in our narrative, an incident had been reported from another unit in the hospital. The police investigation had been abandoned, leading to resentment from the relatives involved and criticism from within the criminal justice system. So this time, a police investigation had to be completed and with success.

Fifth, the hospital was also prosecuted. Being the other suspect it had little to no scope to actively support and protect its employee in public, amplifying the frustration and disappointment among nurses and other professionals.

Finally, the consequences of prosecution for the nurse and other "second victims" in our story and the impact on the nursing profession have been striking as measured by the survey results five years later. When professionals can easily see themselves in Anna's situation, they may be less likely to take up a job in high-risk units or share 
critical information about mistakes, or they may develop defensive routines to avoid honest reporting. Rising level of insecurity and distrust we found in our survey is bad for patient safety. When a level of trust necessary for answerability to ensure a flow of information critical for safety improvements is lacking, patient safety is undermined and the quality of health care at risk.

\section{Conclusions}

This research draws on insight from cognitive psychology in which Dekker (2012) illustrates case by case from aviation, health care and child care the impact of criminalisation of human error. It presents evidence showing the consequences of criminal prosecutions against health professionals. In general, we believe it is fair that people in power assume accountability. What stands out as alarming discovery after the prosecution in our story illustrates the opposite, i.e. a case of accountability without power or control over the conditions in which an incident occurs. Demanding and critical working conditions outside the professionals' control increase the risk of error and impose risk on themselves. The risk of being singled out and thus facing criminal charges when something goes wrong is alarming.

The research provides some strong empirical evidence in support of theoretical considerations discussed earlier in this paper. The evidence indicates that crowding out of professional accountability by legal accountability was facilitated by singling out an individual and framing of an incident as a mistake and neglect. Immature conceptualisation of safety-culture inside the hospital and the absence of specified rules of reporting to the police versus well-established institutionalised procedures inside the criminal justice system paved the way for prosecution. If Dekker is right that the view exists in the legal community that "criminalisation of error is a long-overdue colonisation of rogue areas of professional practice", a predisposition not to let health professionals off the hook this time is not implausible. However, what matters is that this criminal prosecution against a health professional has established a precedent. Given the combined conditions above remain, this can happen again. The prospect of another criminal prosecution is the new reality in health care in Iceland. This is how and why legal accountability can crowd out professional accountability with adverse effect on patient safety and health care in general.

Before concluding this research, we however need to address the deterrence argument on the basis of our empirical findings. As pointed out earlier, in considering patient safety as a critical issue in health care and comparing the two options of accountability, answerability and culpability, these mechanisms have two different objectives. The former aims to improve organisational learning and the latter aims to create deterrence. The question to be addressed here is whether deterrence can achieve the same effect as organisational learning, that is to improve patient safety? On one hand, although ambiguous there is some evidence in the research material which might be interpreted in favour of the deterrence argument, i.e. that nurses are now more likely to report an 


\section{STJÓRNSÝSLA}

unexpected incident than before and thus more likely to keep everyone on their toes. This assumes that the objective of deterrence here is that of professionals at all times keep trying harder to avoid error to occur. On the other hand, apart from ignoring a more sophisticated understanding of human error in health care as discussed above, we cannot assume that a culpability mechanism will create exactly this type of professional response.

Evidence from medical and cognitive science suggest that criminal prosecution may create an adverse effect on patient safety by deterring health professionals seeking a job in high-risk units or by generating investment in defensive posturing rather than improve organisational learning. Therefore, the line of argument in this research can hardly be brushed aside as a mere speculation or theoretical argument only. Although our empirical evidence supports the argument, we however need to better understand the conditions in which human error in health care occurs and the resulting impact on climate of trust, inside as well as outside the health care system. Our findings give implications which beg for a further research into the more specific processes of accounting for unexpected incidents in health care and how these processes affect social relations within health care organisations and beyond.

\section{Acknowledgements}

The author wants to thank Maskina for conducting the survey and for instrumental assistance in processing the results, and the Ministry of Health for a grant provided to cover the cost of the survey. Academic friends and colleagues, home and abroad, deserve my sincere gratitude and respect for much appreciated advice on research methodology and inspiring comments on parts of the manuscript during writing.

\section{Notes}

1 The argument about practicing of defensive medicine has been advanced and accounted for in more recent papers in which the impact of litigation on health care professionals is discussed (Ozeke et al. 2019; Vento et al. 2018; Pellino \& Pellino 2015).

2 See also, Robertson and Long (2018), Dekker (2013) and Wu (2000).

\section{References}

Act No. 41/2007 including later amendments on National Directorate of Health and Public Health Art. 10.

Act No. 88/2008 replacing Act No. 19/1991 on Proceedings of Criminal Cases.

Bovens, M. (2007). "Analysing and Assessing Accountability: A Conceptual Framework”, European Law Journal 13, 505-522.

CPCR, the Chief of Police of the Capital Region (2012a). Police report 04.10.2012. Case no. 007-2012056450.

CPCR, the Chief of Police of the Capital Region (2012b). Police report 15.10.2012. Case no. 007-2012056450.

Dekker, S. (2012). Just Culture: Balancing Safety and Accountability (2 $2^{\text {nd }}$ ed.). Boca Raton: CRC Press Taylor \& Francis Group.

Dekker, S. (2013). Second victim: error, guilt, trauma and resilience. Boca Raton: CRC Press Taylor \& Francis Group. 
DPP, Director of Public Prosecutions (2014). "Prosecution”, published on the DPP's website May $22^{\text {nd }}$ 2014. Retrieved January $3^{\text {rd }} 2020$ from https://www.rikissaksoknari.is/media/frettir/Akaera-birt-aheimasidu.pdf

District Court of Reykjavik (2015). "Reprint of Judgement in Case No. S-514/2014". Retrieved January 2020 from https://www.heradsdomstolar.is/default.aspx?pageid=347c3bb1-8926-11e5-80c6005056bc6a40\&id=08a65d67-d397-4062-977a-f923a7b5ec0c

Greiling, D. (2014). "Accountability and Trust", in M. Bovens, R. Goodin, and T. Schillemans (eds.), The Oxford Handbook of Public Accountability (pp. 617-631). Oxford: Oxford University Press.

Hood. C. (2014). "Accountability and Blame-Avoidance", in M. Bovens, R. Goodin, and T. Schillemans (eds.), The Oxford Handbook of Public Accountability (pp. 603-616). Oxford: Oxford University Press.

Institute of Medicine (2000). To Err Is Human: Building a Safer Health System. Washington, DC: The National Academies Press. doi:10.17226/9728.

Kahneman, D., and Tversky, A. (1974). "Judgement under Uncertainty: Heuristics and Biases", Science 185(4157), 1124-1131. Retrieved from https://science.sciencemag.org/content/185/4157/1124

Krueger, R.A. (1994). Focus Groups: A Practical Guide for Applied Research (2 $2^{\text {nd }}$ ed.). London: Sage Publications.

March, J.G. (1994). A Primer on Decision Making: How Decisions Happen. New York: The Free Press.

Ozeke, O., Ozeke, V., Coskun, O., and Budakoglu, I.I. (2019). "Second victims in health care: current perspectives", Advances in Medical Education and Practice 10, 593-603.

Pellino, I.M., and Pellino, G. (2015). "Consequences of defensive medicine, second victims, and clinicaljudicial syndrome on surgeons' medical practice and on health service”, Updates in surgery 67(4), 331-337. doi:10.1007/s13304-015-0338-8

Perrow, C. (1984). Normal Accidents. New York: Basic Books.

Reason, J. (1990). Human Error. Cambridge: Cambridge University Press.

Research Institute of Pathology (2012). A Medical Legal Autopsy report no. R 108-12.

Robertson, J.J., and Long, B. (2018). "Suffering in silence: Medical error and its impact on health care providers", Journal of Emergency Medicine 54(4), 402-409. Retrieved from https://www.jem-journal. com/article/S0736-4679(17)31167-8/fulltext

Robson, C. (1993). Real World Research: A Resource for Social Scientists and Practitioner-Researchers. Oxford: Blackwell Publishers Ltd.

Sagan, S. (1993). The Limits of Safety. Princeton: Princeton University Press.

Simon, H.A. (1976). Administrative behaviour ( $3^{\text {rd }}$ ed.). New York: Macmillan.

Vento, S., Cainelli, F., and Vallone, A. (2018). "Defensive medicine: it is time to finally slow down an epidemic", World journal of clinical cases 6(11), 406-409. doi:10.12998/wjcc.v6.111.406

Wu, A.W. (2000). "Medical error: The second victim. The doctor who makes the mistake needs help too", BMJ (Clinical research ed.) 320(7237), 726-727. Retrieved from http://www.ncbi.nlm.nih.gov/ $\mathrm{pmc} /$ articles/PMC1117748 
